\title{
O DIREITO DE RESISTIR: LIBERDADE E POLÍTICA EM ESPINOSA
}

\begin{abstract}
Resumo
Paulo Vieira Neto ${ }^{79}$

O Tratado Político é um diagnóstico e a prescrição de um tratamento para os casos em que a política ameaça desaparecer em função da disrupção do corpo social. Caracterizaremos esse tratamento como o direito e a prática da resistência diante dos obstáculos que se opõe à política. Tais obstáculos serão identificados por princípios práticos extraídos principalmente da argumentação do primeiro capítulo do Tratado, que será examinado em suas linhas gerais. Tentaremos mostrar como o limite mínimo da resistência é a restauração de ações que envolvem a máxima distribuição de poder entre os agentes do corpo social e que no limite máximo ela é revolução e instauração do direito e dessa distribuição máxime de poder que, segundo nossa análise irá coincidir com a democracia, ou melhor com as práticas mais democráticas, ainda que aplicadas em regimes monárquicos ou aristocráticos. De fato, a resistência política é implicada pela própria prática da política, como entendida por Espinosa, e é uma dimensão inalienável da liberdade política.
\end{abstract}

Palavras chave: Liberdade, resistência, democracia.

\section{THE RIGHT TO RESIST: FREEDOM AND POLITICS IN SPINOZA}

\begin{abstract}
The Political Treatise give a diagnosis and a prescription for the cases where the politics seems to disappear at the same time of the disassembling of the society. We will understand such prescription as the right and the policy of resisting those things who prevents political action. Those same things will be understood by practical principles who will be find over the first chapter of the Treatise. This chapter will be explained in his general sense and in some of his statements. We will try, then, to show the minimal state of resistance as restauration of democratic principles and the maximum as revolution or instauration of rights. We also will try to show the equality between resistance and the democratical practices that Spinoza advocates for the other forms of government, as monarchy and aristocracy. We will argue that, for Spinoza, the political resistance is an indelible quality of political freedom.
\end{abstract}

Keywords: Freedom, resistance, democracy.

Espinosa, no Tratado Teológico-Político, observa que os supersticiosos recorriam a Deus principalmente nos momentos de infortúnio. Assim também, no desaparecimento da política, o pensamento e a ação se aconselham com a filosofia em um gesto quase supersticioso. Ora, é nesses momentos, mais ainda do que já faz normalmente, que a filosofia deve suprimir toda ilusão, distanciarse maximamente de ser edificante e, enfim, tentar dirigir olhar de seu interlocutor ao que lhe passa despercebido. O conselho que a filosofia pode oferecer nesses casos, consiste em encaminhar o

\footnotetext{
${ }^{79}$ Doutor em Filosofia pela USP e professor do curso de Filosofia na Universidade Federal do Paraná. E-mail: vieiranetopaulinho@gmail.com
} 
solicitante à redescoberta do lugar da política. Isso, com certeza, implica que a filosofia carregue consigo a lucidez necessária para desembaralhar as forças em jogo, os cenários, os interesses e os planos cruzados pelo jogo de perspectiva da contenda político-social, mas exige de forma mais fundamental, ao lado disso, um trabalho de conceito, o de trazer à luz ó lugar em que a política acontece.

Cobra-se da filosofia que ela consiga desenhar novos alvos, ou detectar os pontos sensíveis para a ação social, pontos a partir dos quais se organizariam as vitórias e as derrotas políticas por cima do caos original dos interesses fraturados, como se cobrava de Deus a intervenção milagrosa que restaura a boa fortuna. Mas o que ela deve oferecer, em um primeiro momento, é a lucidez para detectar os alvos e os pontos sensíveis que emergem na própria ação política, os valores que estão virtualmente contidos na crise e que se destacam por conta dela. E quando a ação política parece desaparecer de vista, cabe à filosofia recolocar as coisas em questão e pensar a nova configuração.

Ora, o velho ditado segundo o qual as coisas têm que mudar para continuarem as mesmas não poderia estar mais equivocado, pelo menos nos momentos em que realmente as forças políticas efetivas se esgotam e as forças sociais mais diversas fazem desmoronar o horizonte da prática política. Isso porque a manifestação da crise se dá quando as coisas já mudaram. Daí que, em uma crise política determinada, restauração e revolução surjam como limites máximo e mínimo de uma mudança efetiva já acontecida. Mas essa amplitude de possibilidades só cabe em um espaço instituído pela política e na política, e, portanto, no espaço de um contragolpe na disrupção social e política. A política só se resolve em uma nova política. Um pouco isso é o que parece querer dizer o termo resistência, quando usado no contexto das crises políticas. A resistência se define no ato de criação por meio do qual os agentes políticos constroem o palco no qual a política vai se desenrolar dali para frente. A resistência diz respeito ao futuro e ao presente, mas, com efeito, não faz menos que oferecer um futuro ao desenvolvimento das forças que constituem a política.

Esse talvez seja, aproximadamente, o sentido dos parágrafos iniciais do Tratado Político ${ }^{80}$, quando Espinosa se dá ao trabalho de circunscrever a política como problema e adaptar a audição do leitor a seu timbre muito peculiar. Espinosa pergunta antes de mais nada quando a política acontece. Entretanto, não é tão simples enfrentar a questão antes de tomar alguns cuidados especiais. Dois modelos impedem o intérprete de flagrar esse acontecimento, e integram os dois primeiros grandes obstáculos à ação política, ainda que sejam, até então, apenas duas formas equivocadas de compreensão da política. O primeiro é o que projeta o lugar da política na utopia, o segundo dissolve a política na prática da conspiração - como se os perigos das práticas políticas se aproximassem seja sob

\footnotetext{
${ }^{80}$ Daqui para frente citado como TP, número do capítulo, número do parágrafo, para permitir ao leitor a utilização de outras traduções, e o número da página na edição de Os Pensadores, sem data, São Paulo, Nova Cultural
} 
a figura da mania, seja sob a da paranoia. Dois véus que podem esconder o que realmente interessava pensar e fazer.

Assim, para o Tratado Político, os filósofos-teóricos (e teólogos) por seu lado “... não tinham sobre política vistas que possam ser portas em prática" e se remetiam “... ao domínio da utopia ou da idade de ouro, isto é, a um tempo em que nenhuma instituição era necessária” (p439). Os políticopráticos, por outro lado “... julga-se que estão mais ocupados em preparar armadilhas para os homens do que em dirigi-los pelo melhor". Entre essas duas perspectivas, a do teórico que olha além ou a do prático que mira aquém, se perde precisamente o ângulo que permite olhar diretamente para a política. Onde ela está?

Para Espinosa, falando em momento específico e particular, e situado precisamente na Holanda da década de 70 do século XVII, a política se encontra no campo complexo das afecções e interações humanas, e mais que isso, uma vez que essas interações não fundam um império (humano) dentro de outro império (a natureza) ( TP, I, §6, p. 443), nos conflitos sociais e nas razões que os resolvem. Mas as razões que resolvem os conflitos sociais nem sempre são mero artifício ${ }^{81}$. Esse ponto é de fundamental importância: a política não rompe, ela continua a natureza e um dos motivos pelos quais se perde seu endereço está em cercá-la pela moldura abstrata de uma falsa natureza humana, completamente autonomizada com relação ao restante da Natureza (\$7, p. 444). Além disso, e justamente por força da recusa, Espinosa encontra a política na interação, isso é, no feixe de relações que se estabelece entre humanos-natureza e natureza-humanos ou ainda entre humanos-naturezahumanos ou natureza-humanos-natureza segundo as regras da própria Natureza (TP, I, §9, p445). Portanto um ambiente abstratamente humano, e apenas humano, no qual se desenvolve uma autonomia de ordem diversa da ação da própria Natureza é um não lugar cuja postulação depende de uma crença na espontaneidade absoluta da ação humana. A Natureza não é um deserto habitado pelo homem, nem o mundo humano um plano de outra ordem que sobredetermina a Natureza sem receber, em contrapartida, as determinações dela - não existe aqui, ainda, esse plano que mais tarde vai ser entendido como Espírito (Geist). Não ser um império em um império significa se recolocar na Natureza, sem o que, justamente, não se encontra a política.

Quais são os sintomas da política desencontrada? Há um sintoma exemplar dessa perda de limite na compreensão da política, perda de limite que vem geralmente acompanhada de uma falta de juízo no que diz respeito à avaliação de uma ação política determinada. Ele se manifesta como uma mania que começa por conceber "as emoções que se combatem entre si, em nós, como vícios em que os homens caem por erro próprio" (TP, I, §1, p. 439). Depois, na continuação da mesma narrativa que tem por base a postulação da autonomia absoluta da ação humana, avaliamos os agentes humanos dispostos a “... ridicularizá-los, deplorá-los, reprova-los ou, quando querem parecer mais morais,

\footnotetext{
${ }^{81}$ A esse respeito, Espinosa parece estar respondendo a Hobbes, como sugere Pires Aurélio, Introdução, in Tratado Político, p. XII-XIV, São Paulo, Editora WMF Martins Fontes, 2009, e também, passim, em Lazzeri, Christian. Droit, pouvoir et liberté: Spinoza critique de Hobbes. Paris: PUF, 1998
} 
detestá-los" (idem). Construída a narrativa, o discurso que desloca seu olhar do lugar real em que a política acontece atribui um valor elevado e uma distinção do crítico com relação ao objeto de sua crítica:

“... Julgam assim agir divinamente e elevar-se ao pedestal da sabedoria, prodigalizando toda espécie de louvores a uma natureza humana que em parte alguma existe, e atacando através de seus discursos a que realmente existe." (TP, I, $\S 1, p .439)$

Dessa posição, um tal discurso substitui precisamente o que havia de humano em seu objeto pela projeção de seu desejo - suprimem o que é propriamente humano em nome de seu gosto e então “... Concebem os homens não como são, mas como gostariam que fossem” (idem). O resultado disso é o deslocamento com relação à efetividade de seu objeto, tanto a da Natureza, desqualificada no início como heteronomia, quanto a da humanidade, reduzida ao projeto do desejo de quem a julga segundo a perspectiva do maníaco:

"Daí, por consequência que quase todos, em vez de uma ética, tenham escrito uma sátira, e não tinham sobre política vistas que possam ser postas em prática, devendo a política, tal como a concebem, ser tomada por quimera" (TP, I, §1, p. 439)

Agora, desfeito o mundo (humano-Natureza) e projetados os pólos homem e natureza na inefetividade, segue se a segregação da própria narrativa, entendida como teoria ou como contemplação-especulação que pode ser apartada da prática. Na verdade, sem nenhuma grande surpresa para quem prestou atenção na separação entre Natureza e humanidade, ou entre Natureza e espírito, porque, com efeito, essa distinção já contém em germe a da ação (na natureza) e da contemplação (em espírito). É por isso que:

"Portanto, entre todas as ciências que têm uma aplicação é a política o campo em que a teoria passa por diferir mais da prática, e não há homens que se pense menos próprios para governar o estado do que os teóricos, quer dizer os filósofos" (idem)

Conclusão que, ainda que partindo de premissas semelhantes, contradiz frontalmente a República de Platão em dois pontos essenciais, seja na crítica à posição privilegiada do filósofo no jogo e na compreensão da política, seja na falta de condescendência com o sintoma mais característico da formulação de uma política extranatural, a postulação de uma utopia no lugar da regulação de uma prática efetiva. Importa, no entanto, que se desmonte a narrativa que parte da separação entre natureza e humanidade (dada a autonomia da segunda) porque ela culmina na supressão da aplicabilidade da política e, enfim, na supressão da própria política.

Há um outro sintoma da incompreensão da política: a paranoia. Isso é, os políticos, envolvidos fundamente no imediato de uma ação concreta em nome de interesses concretos, parecem pressupor 
que “... haverá sempre vícios enquanto houver homens ...” (TP, I, § 2, p. 439-40) daí então que o sentido de sua ação seja o de procurar " ... evitar a maldade humana, e isto através de meios cuja longa experiência demonstrou a eficácia, e que homens mais movidos pelo medo que guiados pela Razão têm o costume de utilizar" (TP, I, § 2, p. 439). Se no caso da mania a disjunção entre o humano e a Natureza redundava em um julgamento duro sobre o primeiro, fundamentado na projeção ideal de um modelo perfeito e absoluto de humanidade dotada de uma autonomia absoluta, agora o julgamento duro sobre a humanidade se faz como algo imediato, como uma constatação mais ou menos vaga, mas onipresente e geral, da maldade humana elevada à condição de dado concreto.

Essa segunda posição é bem mais difícil de criticar que a primeira sobretudo porque "Não há dúvida de que os políticos tratam, nos seus escritos, da política com mais êxito do que os filósofos; tendo a experiência por mestra, nada ensinaram, na realidade, que fosse inaplicável" (TP, I, §2 p. 439-40). Mas essa aplicabilidade das regras políticas assim pensadas ainda não recupera o essencial para reconhecer o lugar da ação política. A maldade humana é apenas um aspecto de uma natureza mais complexa, que conhece também a generosidade, a bondade, e afetos mais sociais. As forças disruptivas do corpo social supõe a contrapartida de forças que o recompõe - como o tônus estoico.

Longe, portanto de abandonar um viés prático por tentar corrigir a maldade humana com uma disciplina corretiva, Espinosa implica que a ação política construtiva é tão natural e constante quanto a disruptiva. Além disso, logo adiante, que visando a política "não quis pensar outras instituições, mas o que melhor concorda com a prática" (TP, I, §4, p. 440). Isso é, Espinosa parece falar de um lugar mais próximo ao político que ao teórico - concedida essa maior proximidade, no entanto, cabe cumprir o sentido da distância que o Tratado Político assume com relação à constatação vaga e geral da `maldade humana` pensar ao agente humano como necessariamente maldoso ainda é uma abstração e não coincide exatamente com a experiência efetiva da política. Vimos que o autor denunciava a declaração maníaca de reprovação da humanidade e podemos igualmente julgar que a reprovação paranóica é igualmente denunciada. Mas agora a maneira como se vai denunciar essa outra narrativa é mais diretamente política e implica uma posição política ela mesma, veremos, que é expressa em um princípio que exija do estrategista político a tarefa de pensar sua ação levando em conta a distribuição máxima de poder entre os participantes do jogo político.

Sim, se trata de pensar a ação política concreta, mas sem pressupor apenas a maldade humana. Também há uma concordância entre os homens que se coloca sempre ao lado de seus conflitos. Daí o princípio prático: naturalmente, uma sociedade implica a distribuição de mais poder de ação a seus membros, pela concordância entre eles a fim de minimizar a concentração de poder que se origina na discordância. Esse princípio prático denuncia a simetria nos desvios que levam a perder de vista o lugar onde a política está acontecendo. Na verdade, se recuperarmos o vocabulário da Terceira Parte da Ética ${ }^{82}$, nesse momento, a simetria entre a narrativa maníaca e a paranoica resulta de uma simetria

\footnotetext{
${ }^{82}$ Citaremos a Ética pela mesma edição de Os Pensadores utilizada para o Tratado Político, indicando a parte da
} 
interna mais fundamental, que se dá entre dois afetos, supostos como matiz afetivo que atravessa a narrativa maníaca e a paranoica.

Com efeito, Espinosa define o medo nesses termos:

"O Medo (Metus) é uma tristeza instável nascida da ideia de uma coisa futura ou passada, do resultado da qual duvidamos numa certa medida”. (E, III, Definição das Afecções XIII, p. 327)

Observe-se a simetria disso com a da esperança:

"A esperança (Spes) é uma alegria instável nascida da ideia de uma coisa futura ou passada, do resultado da qual duvidamos numa certa medida”. (E, III, Definição das Afecções XII, p. 327)

O eixo de variação entre esses afetos é a linha divisória entre alegria e tristeza, mas o conteúdo imaginado no afeto implica uma coisa passada ou futura (diríamos, humana ou não humana) cujo efeito acreditamos bom (felicidade) ou mau (tristeza) mas não sabemos com certeza se ocorrerá. É a tonalidade do afeto (a tristeza ou a felicidade) que separa esses afetos e gera, a partir deles, a avaliação do objeto que afeta - o que causa a tristeza é mau e o que causa a felicidade é bom. Mas, logo depois, a narrativa fundada nesses afetos passa do bom ao bem e do mau ao mal. Assim, a postulação de uma natureza humana sublime, que eleva o moralista a uma condição divina e, pelo menos imaginariamente, o coloca em posição de julgar humanidade e Natureza é o objeto que secretamente sustenta uma alegria no ato de julgar (e condenar) - e nesse sentido na medida em que a posição efetiva do moralista corrige sua visão sublime a respeito de si mesmo sua alegria assume o tom da esperança. De outro lado, a constante ameaça da maldade humana, ou o ódio à humanidade que é uma forma de tristeza (E III, VII, p. 326), se torna incerta quando confrontada com o aumento de poder que significa a vida social (o valor negativo dos afetos ligados à solidão dá indícios disso). Isso coloca a prática paranoica, pensada como uma rede de armadilhas e artifícios que têm por finalidade evitar a maldade humana, como uma consequência do medo.

Todavia, observe-se em que sentido tanto o moralista quanto o prático encontram um limite a partir do qual a causa de sua alegria ou tristeza permanece incerta. No caso do moralista, sua natureza humana se vê limitada em seu poder dentro do âmbito da Natureza. Daí talvez a tendência do moralista em postular um império dentro de um império e instituir, ainda que imaginariamente, um lugar apartado da Natureza como espaço de ação privilegiado da natureza humana. O político prático por outro lado é limitado por sua sociabilidade, pela necessidade de viver com aquilo que o ameaça. $\mathrm{O}$ que limite seu poder é outro homem, daí que sua resposta seja a armadilha e artifício que controlam a ação humana, pensada como inevitavelmente ameaçadora.

A resposta à perspectiva que perdia de vista a política por recusar a natureza humana como parte da Natureza, diz respeito, portanto, a uma compreensão da forma como, mesmo tendo seu poder limitado pela Natureza, os homens têm ainda o poder de se organizar politicamente. A resposta, por 
outro lado, à perspectiva que perde de vista a política por medo da natureza humana está em mostrar a concordância natural da humanidade em pontos fundamentais e a irrecusável força de que a razão se investe em função dessa concordância - sem detrimento dos inevitáveis conflitos, mas a política tem a ver exatamente com a solução desses conflitos, em uma medida racional.

Ora, o que haverá de essencial na resposta de Espinosa à avaliação paranóica tem a ver com o papel da razão na solução dos conflitos internos à sociabilidade. Daí que a ação esteja em primeiro plano, mas em um sentido diferente daquele que os políticos práticos a entendem. A razão não implica armadilhas, mas reciprocidade de relação e distribuição de poder. Na verdade, todas as instituições do Tratado Político têm a ver com as maneiras em que essa máxima distribuição de poder pode acontecer em cada um dos regimes de governo históricos. Portanto é só como um todo que o Tratado Político pode responder à política da paranoia.

\section{4}

O que é então resistência política nesse quadro? É a ação política enquanto trata de desmontar dois extremos. Diante do moralista e da política da mania, recuperar a natureza humana efetiva em sua interação com a Natureza, sem o julgamento que eleva o moralista em nome do repúdio à Natureza humana em geral. De outro lado, pensar a política como instrumento de inclusão e construção do corpo social, muito mais que de repressão e punição da disrupção social. Na verdade, a resistência envolve uma atitude política essencialmente positiva: trata-se de recompor ou inventar, pela razão, as instituições em qualquer regime político historicamente constituído. O caráter prático disso está em que o alvo da reconstrução ou da invenção racional são instituições históricas - um possível motivo a partir do qual Espinosa diz não ter a intenção de propor instituições novas. Por outro lado, as instituições históricas ganham um novo sentido e uma nova forma uma vez apropriadas pela razão, daí que ainda haja invenção. É isso o que caracteriza a constante insistência de Espinosa na limitação dos focos de concentração de poder na mão de poucos ou de um só, a constante criação de conselhos a preocupação com a participação popular nos exércitos e a liberdade de expressão e credo.

As proposições 39 e 40 da Ética (E, IV, p. 258) implicam que a razão recolha o que há de comum em um conjunto determinado de coisas, a definição do Tratado da Emenda ${ }^{83}$ (TIE § 21, p. 112) implica que a razão conclua do efeito (in concreto) à necessidade da causa (suposta na medida de sua necessidade, que, nesse caso, não é um dado). Assim, pensar as instituições pela razão, grosso modo, parece envolver as concordâncias entre os participantes das instituições uma vez que elas possam defender seus interesses e em construir assim o tecido social, a partir do que se coloca o problema político de distribuição do poder (TP, II, § 13, p. 446). Quanto menor a possibilidade da inclusão tanto menor a possibilidade de propor na prática uma instituição racional. É justamente aqui que a política

\footnotetext{
${ }^{83}$ Citado pela mesma edição de Os Pensadores que as demais obras, indicando o parágrafo e a página na tradução utilizada, abreviado como TIE.
} 
paranóica difere da política racional. A imposição pelo medo ou a repressão pura e simples, e da mesma forma o artifício que engana os participantes do jogo político, não implica inclusão nem $o$ recolhimento do que há em comum entre os participantes do jogo político.

É verdade que a obediência às instituições que tem valor político é uma obediência entendida de forma meramente objetiva:

“... pouco importa à segurança do Estado que motivo interior têm os homens para bem administrar os negócios, se de fato os administram bem. Com efeito a liberdade da alma, quer dizer a coragem, é virtude privada; a virtude necessária ao estado é a segurança” (TP, II, § 6, p. 443).

Mas é o sentido geral da obediência, isso é a liberdade dos cidadãos, que deve ser preservada pela razão e, a rigor, só pode sê-lo de forma não violenta nesses termos. Entenda-se que a obediência em geral é expressão da solidez do corpo social conquistada com a eficiência da maneira política de administrar o poder e regular as instituições. Não são as instituições apenas, mas as instituições racionais as que garantem a continuidade histórica do Estado - o medo garante coesão social apenas enquanto se alimenta com repressão, mas diante do medo o espaço para a esperança simétrica é garantido, e a coesão de um Estado irracional é muito menos estável que a de um conduzido por instituições racionais. Por isso, principalmente, Espinosa irá lidar com uma certa indiferença os diversos regimes políticos em que se institui o poder, mas vai tratar do conjunto das instituições em cada caso com uma dieta puramente racional, abrindo espaço, em cada caso relevante, para a máxima distribuição de poder entre os participantes do jogo político, ainda que o regime de governo exija a concentração desse poder em um número determinado de focos (um na monarquia, vários na aristocracia, todos na democracia, etc.).

Digo certa indiferença porque o único regime de governo em que as instituições são imediatamente concordantes com a máxima distribuição possível de poder é a democracia. Isso é: a democracia pode ser imediatamente racional, a monarquia e a aristocracia precisam de mediações para isso, e essas mediações vão ter uma feição quase própria a uma democracia. Daí a proliferação de conselhos e a constante preocupação, que atravessa todo o Tratado Político, com a maior participação popular possível (TP, VII, § 4, p. 472; VIII, § 5, 6, p. 486; VIII, § 28, 29, p. 495). Não se trata exatamente de mascarar os regimes de governo, mas de, concedendo sua presença histórica e sua evidente aplicabilidade prática, conferir-lhes a feição mais racional possível o que, pela própria natureza da razão, implica uma democratização inevitável no âmbito do funcionamento e do equilíbrio interno das instituições tanto na monarquia quanto na aristocracia.

Então podemos dar mais um passo na explicação do que seja resistência política no quadro geral do que pensa Espinosa no Tratado Político. A resistência consiste na racionalização democratizante das instituições que garantem ao Estado, qualquer que seja o regime de governo, o estado mais próximo da máxima distribuição de poder, em função disso da maior estabilidade natural (não violenta). 
Todavia a resistência é necessária apenas quando, ou justamente quando, a política desaparece na forma paranoica ou na mania moralista. De forma ainda mais geral: quando o poder político se concentra e assume formas muito menos includentes do que exige a amplitude e a estabilidade natural do tecido social. Em especial, a resistência se impõe diante das mais variadas formas da tirania - não desenvolveremos isso aqui, mas sugerimos ao leitor que a tirania possa ser desenvolvida em tantas formas históricas quantas são as dos regimes de governo (tirania, oligarquia, demagogia ou de maneira mais ampla em qualquer forma de ditadura). Fica dado como evidente que Espinosa analisa os regimes de governo apenas em sua forma comprometida com a razão, e a explicação para a tirania será antes de mais nada, a violência dos tiranos de um lado, a ignorância e a passividade dos cidadãos de outro.

É nesse quadro que aparece a questão mais delicada a respeito da resistência. Em um corpo político existente a resistência é a garantia constante da estabilidade do regime político e do corpo social. Em uma tirania, a disrupção do regime político aponta para a destruição do corpo social. Se isso acontece de uma forma dramaticamente intensa, o que é o caso em toda tirania, mas é mais evidente nas mais violentas, o corpo social está destruído. Nesse caso a resistência não pode mais ser uma restauração mas a instituição de uma nova distribuição de poder. Em que momento a resistência justifica a revolução como forma de instituir um regime não tirânico no lugar de um tirânico?

\section{5}

Nos capítulos iniciais do Tratado Político, Espinosa estabelece uma equação entre o direito e o poder de agir em cada agente político (TP, I, §8, p. 444) - e isso antes desse agente ser um cidadão ou súdito. Na cidadania e no estado de súdito esse direito só está submetido ao poder maior da soberania como poder de todos os que integram o corpo político. Daí a situação complexa que se arma no jogo político.

De um lado cada agente, em sua própria natureza, agindo segundo seu esforço para perseverar em seu ser segundo suas próprias regras, e se manifestando por seus próprios afetos ${ }^{84}$. Nesse agente há regras que se impõe na relação com outras naturezas, supondo essas outras naturezas como diferentes e essa relação como uma imposição, e regras que se originam em razão de sua natureza, no que ela tem em comum com as outras naturezas, sem imposição recíproca. Seguir a razão é algo que diz respeito à última alternativa. No que concerne à primeira abre-se o espaço para a servidão se, e apenas se, a natureza externa que impõe sua ação não concorda com a natureza daquele a que isso se impõe (TP, I, $\S 9,10$, p. 445). Observe-se que ainda que a razão imponha regras necessárias, ela não o faz diminuindo a liberdade do agente. A liberdade está em jogo não contra a necessidade, mas pela disputa entre as duas naturezas. Assim se uma outra natureza se impõe a nós por algo que temos em comum não se diminui a liberdade daquele a quem isso se impõe, é possível inclusive apontar o caso

\footnotetext{
${ }^{84}$ Cf. Chauí, Marilena; Espinosa poder e liberdade, in Filosofia política moderna, 2006. Disponível em http://biblotecavirtual.clacso.org.ar/ar/libros/secret/filopolmpt/06_chaui.pdf.
} 
em que essas duas naturezas, juntas aumentam seu poder de ação. Por outro lado, quando uma natureza submete outra em sua diversidade isso diminui o poder de ação daquela que se submete.

É possível pensar a relação entre duas naturezas, esquematicamente, como uma soma vetorial, em oposição à soma escalar. Isso é, dois agentes se tornam mais fortes ou mais fracos segundo a concordância entre suas naturezas e, portanto, a multiplicação de agentes no corpo de uma sociedade não significa um aumento linear de poder. O que é um primeiro ponto para levarmos em consideração.

Agora, segundo o Tratado Político, podemos operar contra nossa natureza pela imposição de outra. Entenda-se corretamente: operamos contra nossa natureza quando nossa operação vem carregada de uma diminuição de nosso poder (TP, I, § 10, p. 445). Como a soma dos agentes em um corpo social não aumenta nosso poder linearmente, coloca-se a questão de saber se as relações entre os agentes, no corpo complexo da sociedade, vão concordar ou discordar de suas naturezas. Daí um cálculo de máximo e mínimo. A forma de sociabilidade que garante o mínimo de diminuição de poder do corpo complexo e a que garante o máximo demarcam dois limites: a sociedade ótima e a péssima.

A situação de cada agente dentro desses limites, os limites incluídos, pode ser a de quem impõe seu poder sobre outro - o que não é imediatamente um aumento de seu poder - ou a de quem se submete a um poder maior operando contra sua natureza. Na sociedade péssima esse quadro institui a tirania. Ora, quando a tirania se aplica sobre uma porção do corpo social que, por si mesma, deveria acumular mais poder que o dos tiranos o conflito se torna inevitável. Os princípios para compreender isso vêm da Terceira Parte da Ética: a diminuição de poder dos súditos é sentida como uma gama de afetos de tristeza, entre os quais o ódio. A instituição da tirania reflete na contrapartida de uma resistência proporcional à violência da tirania - não se trata de dizer que o poder é um jogo de soma zero, o poder dos que se submetem à tirania é efetivamente maior que o poder do tirano. Trata-se de dizer que a estabilidade do corpo social depende de sua capacidade de se aproximar do caso ótimo. Daí que a máxima distribuição de poder seja desejável e que o cálculo político consista em aproximarse dela.

Mas o que acontece, na direção contrária, quando nos aproximamos da tirania? Nesse caso, o tecido social se rompe e temos a reinstituição de um novo corpo social. Esse é o caso da revolução. Se nas sociedades mais próximas da distribuição ótima de poder aumenta nosso poder de resistência, nas sociedades mais distantes esse poder de resistência se desloca para a tendência a romper com o corpo político e fundar outro.

\section{6}

Ora, poder de agir daqueles que reagem à tirania instaura seu direito, na verdade, a equação entre poder e direito concede espaço à possibilidade do reconhecimento, sob a guarda de um novo direito, da revolução contra uma tirania. O princípio segundo o qual isso pode ser pensado - o momento singular da instauração de um novo direito - aparece no início do Tratado Político: 
“... chamo livre a um homem na medida em que vive sob a conduta da razão porque, nesta mesma medida é determinado a agir por causas que podem ser adequadamente conhecidas unicamente a través da sua natureza ainda que essas causa o determinem necessariamente a agir". $(T P, I, \S 7)$

O texto usa expressamente o mesmo termo agir (e a expressão `ser determinado a agir`) que já se encontrava na Primeira Parte da Ética, na definição VII (E, I, Def VII, p. 351). Aliás, a liberdade humana é apresentada aqui com os mesmos termos de que se servia Espinosa, na Ética, para definir a liberdade divina, que também consistia em ser determinado a agir apenas por sua própria natureza. $\mathrm{O}$ que isso quer dizer? Quer dizer que uma ação que aparece para nós como adequada à razão vem acompanhada de um sintoma, a saber, de que nossa própria natureza concorda integralmente com essa ação, e ela é para nós a mesma coisa que seria uma ação espontânea. O que, embora seja verdade no caso divino, no nosso caso não é verdade: é que espontaneamente agiríamos da mesma forma, e a causa que nos determinou a agir não o fez de forma diferente daquela que faria apenas pela determinação da nossa natureza.

Como isso é possível na política? Simplesmente Espinosa parece estar implicando que a possibilidade de resolver a ação coletiva pela razão envolve que os agentes possam maximamente se determinar pela sua razão - e que na verdade a sociabilidade é acolhida de forma racional e livre, sempre. Não se trata aqui de uma relação apenas entre agentes humanos, é nosso encaixe na Natureza como um todo e todas as relações cruzadas entre as coisas e a ação humana que são passíveis de se desenvolver sob a guarda da razão. Nesse sentido toda tirania é antecedente de uma revolução e toda democracia de uma restauração do verdadeiro jogo político.

Então, o que o longo movimento argumentativo, que atravessa o Tratado Político de seus primeiros parágrafos até as receitas práticas de governo em cada regime tem a nos ensinar sobre a noção de resistência política pode ser resumido em alguns princípios práticos bastante precisos. Primeiro: a resistência política equivale à estratégia de manutenção ou de instituição da máxima distribuição de poder político a todos os agentes do corpo social (e algo mais que isso, se pensamos a imersão do corpo social na Natureza). Segundo: o mínimo da resistência é a restauração do fluxo de poder democrático, que se expressa na possibilidade de agir segundo a razão, o máximo é a revolução que institui esse fluxo uma vez ele tenha sido interrompido pelo acúmulo tirânico de poder. Terceiro o direito é expressão desse fluxo de poder, se institui e se estrutura nos limites dos princípios anteriores. E, por fim: o objeto último da política faz coincidir a liberdade dos agentes com a sua cidadania (e com a possibilidade de satisfação das suas necessidades).

Para Espinosa então, quando a política é dirigida pela razão, liberdade, direito e poder coincidem completamente na cidadania. Esse talvez seja o segredo dos corpos políticos mais duradouros, a proximidade dessa coincidência. Ao mesmo tempo podemos esclarecer o que é o direito à resistência na política de Espinosa. É a própria instauração da ação racional como direito e cidadania. A resistência é o lugar onde acontece a política. 


\section{REFERÊNCIAS}

CHAUÍ, Marilena; Espinosa poder e liberdade, in Filosofia política moderna, 2006. Disponível em http://biblotecavirtual.clacso.org.ar/ar/libros/secret/filopolmpt/06_chaui.pdf.

ESPINOSA, B. Spinoza Opera. Ed. de Carl Gebhardt. Heidelberg: Carl Winter, 4vols, 1972 [1ª ed. 1925].

. Obras, em Os Pensadores, sem data, São Paulo, Nova Cultural.

Tratado Político, Tradução, introdução e notas de Diogo Pires Aurélio; revisão da tradução Homero Santiago, p. XII-XIV, São Paulo, Editora WMF Martins Fontes, 2009.

LAZZERI, Christian. Droit, pouvoir et liberté: Spinoza critique de Hobbes. Paris: PUF, 1998.

PIRES AURÉLIO, Diogo, Introdução, in Tratado Político, São Paulo, Editora WMF Martins Fontes, 2009.

Recebido: setembro/2018

Aprovado: novembro/2018 